G368(P) DYNAMICS OF DEGREE BREACH STRUCTURE OF LIVER AND DEGREE PORTAL HYPERTENSION IN CHILDREN WITH AUTOIMMUNE HEPATITIS AND WILSON'S DESEASE

GV Volynets, NN Evlyukhina, AN Filin, NL Pakhomovskaya. Gastroenterology, Federal State Budgetary Institution (Scientific Centre of Children Health), Moscow, Russian Federation

10.1136/archdischild-2015-308599.324

Aim To determine the degree of disruption of the structure of the liver and the severity of portal hypertension and its dynamics during therapy in patients with autoimmune hepatitis (AIH) and Wilson's disease (WD) in children based on a points system determining the degree of disruption of the structure of the liver.

Methods Analysis of case histories of 176 child at the age from 1 to 17 years (mean age $11.8 \pm 3.5$ years) with WD $(55.4 \%)$ and $\mathrm{AIH}(42.6 \%)$. Of them with cirrhosis $-40.4 \%$, without cirrhosis - 59.6\%. 49 children $(27.8 \%)$ liver transplantation was performed.

Results In children with AIH degree of disruption of the liver structure was $20.4 \pm 9.2 \%$. In children with liver cirrhosis in the outcome of AIH $-24.8 \pm 8.3 \%$, without cirrhosis - $13.2 \pm 5.5 \%$ $(\mathrm{p}<0.001)$. In children with WD degree of disruption of the liver structure at first hospitalisation was $17.7 \pm 12.1 \%(\mathrm{p}=$ $0.305)$. In children with liver cirrhosis in the outcome WD -32.4 $\pm 9.2 \%$, without cirrhosis $-10.5 \pm 4.0 \%$ ( $p<0.001)$. In 49 children, who underwent liver transplantation, the degree of disruption of liver structure was $45.2 \pm 16.2 \%$ ( $p<0.001)$. The degree of disruption of liver structure with AIH after 6 months of therapy $-15.1 \pm 8.0 \%(\mathrm{p}=0.007)$, in children with liver cirrhosis in the outcome of AIH $-16.9 \pm 8.9 \%(p<0.001)$, without cirrhosis $-11.0 \pm 2.3 \%(\mathrm{p}=0.276)$. After 12 months of therapy, the degree of disruption of the structure of the liver in children with AIH $-13.4 \pm 5.2 \%(\mathrm{p}<0.001)$, in children with liver cirrhosis in the outcome of AIH $-15.6 \pm 5.3 \%(\mathrm{p}<0.001)$, in children without cirrhosis was $9.8 \pm 1.8 \%(\mathrm{p}=0.139)$.

Conclusion Scoring system degree of disturbance of the liver structure and severity of portal hypertension can be used as an objective criterion for evaluating the degree of disturbance of liver structure changes in their dynamics on the background of the therapy.

\section{G369(P) PORTAL CAVERNOMA AND THE CHALLENGES FACED IN EARLY INFANCY}

1,2ND Ruth, 'I Van Mourik. 'Hepatology, Birmingham Children's Hospital NHS Foundation Trust, Birmingham, UK; ${ }^{2}$ Medical School, University of Birmingham, Birmingham, UK

\subsection{6/archdischild-2015-308599.325}

We describe the case of an ex 25/40 gestation infant initially referred with failure to thrive to her local hospital. She had a background of tracheo-oesophageal fistula and had a degree of chronic lung disease for which she had home oxygen. She was the first born child to unrelated caucasian parents, and was placed in foster care prior to discharge due to parental drug abuse. Examination at referral centre revealed marked splenomegaly. Ultrasound scan revealed portal cavernoma and she was referred to a tertiary unit for investigation and management.

Prior to review, the patient suffered a significant PR bleed at a corrected gestational age of 4 months. Following transfer she suffered 4 further bleeds, 2 of which resulted in cardiac arrest. This is an unusual presentation in a child so young. She had endoscopy and banding, as well as sclerotherapy on 4 separate ocasions, each time suffering a further bleed 3 days later. She was commenced on anti-hypertensive medications with minimal effect. Octreotide did control the bleeding but each time this was weaned she suffered further bleeding. She went on to have splenorenal shunt surgery which abated the bleeds temporarily prior to eventual splenectomy. She had a prolonged intensive care admission and was eventually discharged home on.

This case report highlights the sequelae of prematurity as well as management of an unusual presentation of portal cavernoma in a patient of this age.

\section{G370(P) FICTITIOUS ILLNESS DUE TO CHRONIC LAXATIVE POISONING: A CASE REPORT}

DC Atukorale, R Jayatunga. Sandwell \& West Birmingham Hospitals NHS Trust, Birmingham, UK

\subsection{6/archdischild-2015-308599.326}

Aims Fictitious Illness is a form of child abuse, where a perpetrator makes a child appear sick by either fabricating symptoms or actually causing harm to the child, in order to gain attention. The child could be poisoned by the perpetrator to induce the symptoms.

Method We report the course of a girl who presented with chronic diarrhoea and severe failure to thrive, as a result of chronic laxative poisoning, by her mother. A review of the English literature (PubMed) revealed only 1 other similar case report in an infant.

Results A girl was admitted repeatedly (11 admissions in 11 months) to hospital between the ages of 3 weeks and 11 months for further evaluation of chronic diarrhoea and severe growth faltering. Her mother reported that she had vomiting, poor feeding and diarrhoea. Her birth weight was $4.07 \mathrm{~kg}\left(91^{\text {st }}\right.$ centile) but at 11 months she was emaciated, weighing only $6.94 \mathrm{~kg}$ (well below the $3^{\text {rd }}$ centile).

She had been extensively investigated for a cause, including regular blood, stool and urine tests, imaging and intestinal biopsies. As the aetiology for her symptoms was not found, she was managed for possible gastro-oesophagial reflux and cow's milk protein intolerance, although neither were proven. But her symptoms continued, despite a multi-disciplinary approach from paediatricians, tertiary gastroenterologists, dieticians, community nursing and health visitor, causing significant malnutrition and delayed development, by 1 year of age.

Incidental finding of Bisacodyl with the child's belongings during an admission led to the suspicion of laxative poisoning. It was confirmed with positive urine toxicology for Bisacodyl on two separate occasions.

Mother was removed from the care of the child with involvement of social services. Following this, she made excellent progress and her weight increased from $6.925 \mathrm{~kg}$ to 9.35 $\mathrm{kg}$ within a period of $31 / 2$ weeks giving an average weight gain of $692 \mathrm{~g}$ per week. In foster care her development returned to normality.

Conclusions We highlight the need to consider this rare diagnosis when extensive investigations fail to identify an underlying cause in infants with severe weight loss due to protracted diarrhoea. 